\title{
Burden of prehypertension among adults in Kenya: a retrospective analysis of findings from the Healthy Heart Africa (HHA) Programme
}

Jared O. Mecha ${ }^{1 *}$ (D), Elizabeth N. Kubo ${ }^{1}$, Collins O. Odhiambo ${ }^{1}$, Freda G. Kinoti ${ }^{1}$, Kennedy Njau², Gerald Yonga ${ }^{1,2}$ and Elijah N. Ogola ${ }^{1,2}$

\begin{abstract}
Background: Hypertension is the leading risk factor for mortality globally. African countries, including Kenya, have a high and rising prevalence of hypertension. Prehypertension is associated with an increased risk of progression to overt hypertension and a higher risk of cardiovascular disease and mortality. Despite this, little is documented on the prevalence and distribution of prehypertension in sub-Saharan Africa. This study sought to estimate the overall burden of prehypertension in Kenyan adults enrolled in a large hypertension control programme, Healthy Heart Africa. The distribution and determinants of prehypertension in the sample were explored as secondary objectives.

Methods: This was a post hoc analysis of cross-sectional data obtained from population-level blood pressure (BP) screening of adults aged $\geq 18$ years in the community and ambulatory care facilities in 17/47 sub-national administrative units in Kenya. All participants with a complete record for systolic and diastolic BP were included. Descriptive analyses were performed for sociodemographic characteristics. Pearson's chi-square test was used to assess differences in categorical variables. Multivariate logistic regression analysis was performed to identify factors independently associated with prehypertension.

Results: Of 5,985,185 participant records that were included in the analysis, 34\% were men (mean age: 45 [SD 2.9] years). The majority (63\%) lived in rural Kenya. The prevalence of prehypertension was $54.5 \%$ and that of hypertension was $20.8 \%$. Characteristics that were independently associated with prehypertension (adjusted odds ratio [95\% Cl]) included male sex (1.23 [ \pm 0.0023$], p<0.001$ for all age groups $>25$ years) and rural residence $(1.60$ $[ \pm 0.023], p<0.001)$.

Conclusions: Approximately one in every two Kenyan adults has prehypertension. This calls for urgent development and roll-out of a national BP screening and control programme. It also provides a strong basis for the formulation of multisectoral national policies that will ensure implementation of evidence-based, low-cost public health interventions geared towards primary prevention of hypertension, especially in population groups that are traditionally considered at low risk, such as young adults and rural residents.
\end{abstract}

Keywords: Prehypertension, Prevalence, Cardiovascular disease, Kenya, Sub-Saharan Africa

\footnotetext{
* Correspondence: jared.mecha@uonbi.ac.ke

${ }^{1}$ Department of Clinical Medicine and Therapeutics, University of Nairobi,

Nairobi, Kenya

Full list of author information is available at the end of the article
}

(c) The Author(s). 2020 Open Access This article is distributed under the terms of the Creative Commons Attribution 4.0 International License (http://creativecommons.org/licenses/by/4.0/) which permits unrestricted use, distribution, and reproduction in any medium, provided you give appropriate credit to the original author(s) and the source, provide a link to the Creative Commons license, and indicate if changes were made. The Creative Commons Public Domain Dedication waiver (http://creativecommons.org/publicdomain/zero/1.0/) applies to the data made available in this article, unless otherwise stated. 


\section{Background}

Raised blood pressure (BP) is the leading risk factor for global morbidity and mortality [1]. Africa has the highest age-adjusted prevalence of hypertension globally [2]. A meta-analysis of recent studies in Africa showed a prevalence of $30 \%$, with a progressive rise with increasing age [3]. In Kenya, a recent national survey found a prevalence of $24.5 \%$ [4], consistent with the results of the May Measurement Month global screening exercise (MMM17) in which $24.6 \%$ of those screened were hypertensive [5]. Prehypertension as a BP category was introduced in 2003 by the Seventh Joint National Committee on Prevention, Detection, Evaluation and Treatment of High Blood Pressure (JNC-7) [6] to highlight the excess risk associated with BP in this range [7]. The excess risk associated with elevated $\mathrm{BP}$ begins at a systolic BP of $115 \mathrm{mmHg}$ and a diastolic BP of $75 \mathrm{mmHg}$. Prehypertension is, therefore, not only associated with a higher risk of transition to overt hypertension but is also independently associated with a higher cardiovascular risk. Given the link between the continuum of prehypertension, hypertension, and ultimately cardiovascular disease morbidity and mortality, early identification of prehypertension may be a critical first step in increasing awareness and designing and implementing early preventive interventions.

Despite the public health threat posed, there is a paucity of data on the prevalence and distribution of prehypertension in sub-Saharan Africa. A skewed focus on infectious diseases, maternal and child health and acute care, compounded by weak health systems, has led to the general neglect of cardiovascular disease risk factor identification and mitigation [8]. Consequently, people with prehypertension frequently go undetected and are not followed up to prevent progression. The identification of prehypertension presents a relatively low-cost opportunity to initiate cardiovascular risk reduction for a large proportion of the population. Although two previous Kenyan studies have documented high prevalence of prehypertension (53 and 59\%) [9, 10], there is a lack of general awareness on the need for screening and followup for prehypertension.

The primary objective of this study was to estimate the burden of prehypertension in a population of Kenyan adults who were enrolled in a large hypertension screening, treatment and control programme, Healthy Heart Africa (HHA). Secondary objectives were to explore the distribution and determinants of prehypertension in the study population.

\section{Methods}

\section{Study design}

This was a post hoc analysis of cross-sectional survey data obtained from a population-level BP screening campaign that was part of the HHA programme. HHA was conducted through a public-private partnership initiative between the Kenya Ministry of Health and AstraZeneca PLC, from February 2015 to October 2018.

\section{Study setting}

Details of the HHA programme have been published previously [11]. In summary, the programme was implemented in 17 out of a possible 47 Kenyan counties between March 2015 and March 2016. The main goal of the HHA programme was to reduce barriers to hypertension screening, identification, referral and treatment, through several approaches, including: (1) education and raising awareness of hypertension among healthcare workers (HCWs) and the general public; (2) opt-out facility and community-based screening for hypertension by trained lay providers, especially in non-traditional screening settings such as religious and commercial centres; (3) training of HCWs on the Kenya Ministry of Health-approved hypertension screening and treatment protocol in order to enhance hypertension diagnosis and treatment; and (4) provision of a consistent supply of quality-assured medicines for hypertension treatment.

Standardised registers were used to collect participant information. These data were checked for accuracy, deidentified and uploaded onto a central database monthly.

\section{Participants}

The study population was drawn from health facilities and their respective catchment communities. Health facilitybased participants comprised adult patients aged 18 years and above who were seeking routine ambulatory health services. Community-based participants were adults aged 18 years and above who volunteered for BP screening at strategically located booths at non-clinical community settings. Trained laypersons conducted the BP screening using standardised protocols [12]. At a minimum, the trained laypersons were high school graduates. Briefly, BP was measured using CE marked Omron M3 digital devises (Omron Healthcare, Kyoto, Japan) with the participant seated in an upright, relaxed position. An appropriate cuff size was selected for each participant, and the cuff was wrapped around the left arm, supported at the level of the heart. Two readings were taken 2 min apart, and the average of the two was recorded. To ensure reliability and validity of the measurements, the lay field assistants received standardised training on BP measurement and the use of standard operating procedures. Trained nurses also carried out regular supportive supervision and provided mentorship and support.

All participants who had a recorded systolic and diastolic BP were included in the analysis. Out of 5,985,185 participants who were screened, 5790 and 6861 had missing systolic and diastolic BP readings, respectively, and were therefore excluded from the analysis. 


\section{Data handling}

The de-identified analysis database was obtained from the central database in a CSV command delimiter, UTF16 LE file encoding format. Data were then imported to RStudio using the read.delim function. Data cleaning, decoding, recoding and analysis were performed using RStudio.

\section{Variables}

The main outcome variable of interest was prehypertension. This was defined as a systolic BP of 120-139 $\mathrm{mmHg}$ and/or diastolic BP of $80-89 \mathrm{mmHg}$ [6]. Other outcomes of interest were normotension and hypertension. Normotension was defined as a systolic BP $\leq 120$ $\mathrm{mmHg}$ and a diastolic BP $\leq 80 \mathrm{mmHg}$ [6]. Hypertension was defined as a systolic BP $\geq 140 \mathrm{mmHg}$ and/or a diastolic BP $\geq 90 \mathrm{mmHg}$ [6].

Predictor variables included age (categorized into six age groups: $18-25,26-35,36-45,46-55,56-65$ and $65+$ years), sex and place of residence (urban/rural).

A negligible number of participants had missing data for the various variables of interest and were therefore omitted from the final analysis.

\section{Statistical analysis}

Descriptive analyses were performed for sociodemographic characteristics of the study population. Categorical variables were presented using proportions. Continuous variables were presented using means with corresponding standard deviations (SDs). Pearson's chi-square test was used to assess differences in categorical variables. Multivariate logistic regression analysis was performed to identify factors independently associated with prehypertension. Crude and adjusted odds ratios (aORs) are presented. All statistical tests were two-sided, and $p$ values $<0.05$ were considered statistically significant. All analyses were performed using RStudio (2015), RStudio: Integrated Development for $\mathrm{R}$ (RStudio, Inc., Boston, MA).

\section{Results}

Out of a total of 5,985,185 participant records that were analysed, 2,057,674 (34\%) were men. The overall mean age was 45 years (SD 2.9). Men had a mean age of 47 years (SD 1.13) and were older than women who had a mean age of 43 years (SD 1.7). Approximately $63 \%$ of the participants were rural dwellers.

\section{Burden of abnormal blood pressure}

The distribution of prehypertension and hypertension by participant characteristics is presented in Table 1.

The overall burden of prehypertension was $54.5 \%$ and that of hypertension was $20.8 \%$. The prevalence of prehypertension was higher among men (59\%) compared to women $(52 \%) \quad(p<0.001)$. Similarly, the burden of
Table 1 Burden of prehypertension and hypertension by participant characteristics $(n=5,985,185)$

\begin{tabular}{|c|c|c|c|}
\hline Characteristics & $\begin{array}{l}\text { Normal } \\
N=1,478,920\end{array}$ & $\begin{array}{l}\text { Prehypertension } \\
N=3,262,387\end{array}$ & $\begin{array}{l}\text { Hypertension } \\
N=1,243,878\end{array}$ \\
\hline Prevalence, \% (Cl) & $24.7( \pm 0.38)$ & $54.5 \%( \pm 1.39)$ & $20.8( \pm 0.2)$ \\
\hline \multicolumn{4}{|l|}{ Age (years) } \\
\hline mean (SD) & $39( \pm 0.02)$ & $46( \pm 0.02)$ & $51( \pm 0.02)$ \\
\hline \multicolumn{4}{|l|}{ Age group, \%, (Cl) } \\
\hline $18-25, n=767,730$ & $45 \%( \pm 0.1)$ & $47 \%( \pm 0.3)$ & $8 \%( \pm 0.6)$ \\
\hline $26-35, n=1,488,388$ & $35 \%( \pm 0.1)$ & $53 \%( \pm 0.2)$ & $12 \%( \pm 0.1)$ \\
\hline $36-45, n=1,305,740$ & $25 \%( \pm 0.4)$ & $57 \%( \pm 0.3)$ & $18 \%( \pm 0.3)$ \\
\hline $46-55, n=964,863$ & $15 \%( \pm 0.5)$ & $58 \%( \pm 0.6)$ & $27 \%( \pm 0.4)$ \\
\hline $56-65, n=645,912$ & $9 \%( \pm 0.3)$ & $57 \%( \pm 0.4)$ & $34 \%( \pm 0.5)$ \\
\hline $65+, n=534,324$ & $9 \%( \pm 0.2)$ & $63 \%( \pm 0.3)$ & $28 \%( \pm 0.4)$ \\
\hline \multicolumn{4}{|l|}{ Sex, \% (Cl) } \\
\hline male, $n=2,057,694$ & $19 \%( \pm 0.5)$ & $59 \%( \pm 0.2)$ & $22 \%( \pm 0.3)$ \\
\hline female, $n=3,903,062$ & $28 \%( \pm 0.1)$ & $52 \%( \pm 0.1)$ & $20 \%( \pm 0.1)$ \\
\hline \multicolumn{4}{|l|}{ Residence, \%, (Cl) } \\
\hline Urban, $n=468,820$ & $22 \%( \pm 0.3)$ & $55 \%( \pm 0.2)$ & $24 \%( \pm 0.4)$ \\
\hline Rural, $n=843,944$ & $14 \%( \pm 0.3)$ & $57 \%( \pm 0.2)$ & $29 \%( \pm 0.2)$ \\
\hline
\end{tabular}

hypertension was higher among men (22.0\%) compared to women $(20 \%)(p<0.001)$. The highest proportion of prehypertension (63\%) was recorded among those aged 65 years and older. More rural residents had prehypertension compared to urban dwellers ( $57 \%$ vs $55 \%$, respectively) $(p<0.001)$. Likewise, more rural dwellers had hypertension compared to their urban counterparts (29\% vs $24 \%$, respectively) $(p<0.001)$.

\section{Burden of prehypertension by age group}

Figure 1 shows the proportion of prehypertension by age group. Overall, the burden increased with increasing age.

\section{Independent predictors of prehypertension}

Independent predictors of prehypertension are presented in Table 2. Characteristics that were independently associated with prehypertension (aOR [95\% confidence interval]) included male sex (1.23 $[ \pm 0.0023], p<0.001$ for all age groups $>25$ years $)$ and rural residence $(1.60[ \pm 0.023]$, $p<0.001)$.

\section{Discussion}

HHA was the largest hypertension screening program to be conducted in Kenya, and was planned to raise awareness on hypertension along with providing education, training and treatment. This study demonstrated that approximately one in every two Kenyan adults has prehypertension. The condition is more common among men than women, and the burden increases with increasing age. The rise begins very early in the third decade of life, a 


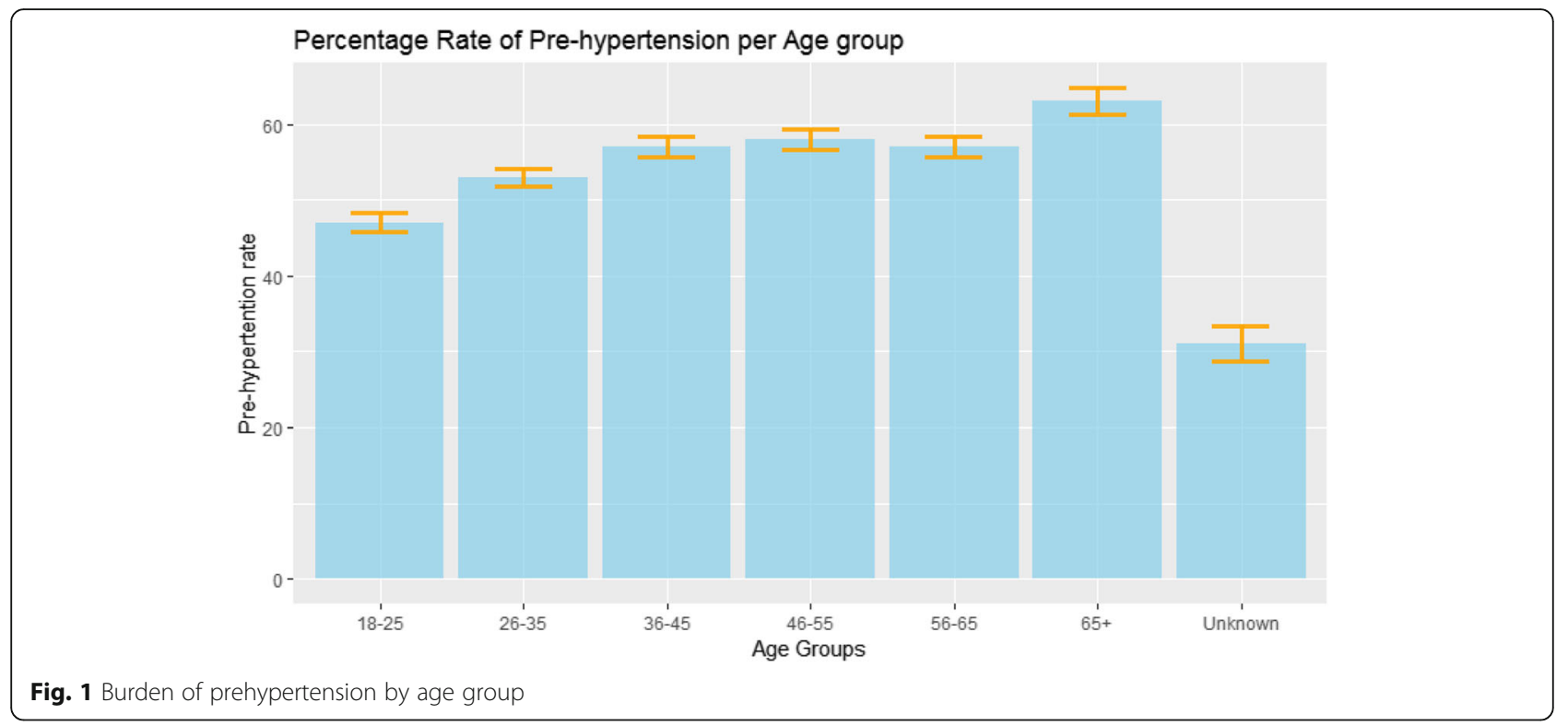

population often overlooked by hypertension control programmes. This is a worrying finding in view of the excess cardiovascular risk associated with prehypertension and underscores the need for early screening programmes and population-wide primary prevention measures. Previous research has documented a $27 \%$ increase in all-cause and a $66 \%$ increase in cardiovascular disease mortality associated with prehypertension [13]. The high burden of prehypertension documented here is also of concern in view of the associated risk of transition to hypertension. Identification of prehypertension thus presents a significant opportunity to improve the cardiovascular risk of a significant proportion of the population.

Although the burden of prehypertension documented here is within the $53-59.3 \%$ range previously reported in
Kenya $[9,10]$, it is higher than some of the reports in the literature which showed a prevalence of $31-48.9 \%$ in nonAfrican contexts. Our findings are consistent with growing evidence that, globally, Africa has the highest rates of ageadjusted prevalence of hypertension [14-19].

Similar to prior studies, men were more likely to have prehypertension than women $[15,17-21]$. This may partly be related to the protection rendered to women by hormonal factors as well as pregnancy and child birth-related factors [22].

Our analyses found a slightly higher proportion of prehypertension among rural residents. This could be attributed to lower rates of screening and diagnosis among rural compared with urban residents. The Kenya STEPwise Survey documented that $60.7 \%$ of rural residents

Table 2 Characteristics associated with prehypertension

\begin{tabular}{|c|c|c|c|c|}
\hline Variable & OR $(95 \% \mathrm{Cl})$ & $p$-value & $\mathrm{aOR}(95 \% \mathrm{Cl})$ & $p$-value \\
\hline \multicolumn{5}{|l|}{ Sex } \\
\hline Female & ref & ref & ref & ref \\
\hline Male & $1.245( \pm 0.0017)$ & $<0.001$ & $1.229( \pm 0.0023)$ & $<0.001$ \\
\hline \multicolumn{5}{|l|}{ Age group (yrs.) } \\
\hline factor(Age group) 18-25 & ref & ref & ref & ref \\
\hline factor(Age group) 26-35 & $1.516( \pm 0.015)$ & $<0.001$ & $1.411( \pm 0.0019)$ & $<0.001$ \\
\hline factor(Age group) 36-45 & $1.661( \pm 0.016)$ & $<0.001$ & $1.523( \pm 0.0015)$ & $<0.001$ \\
\hline factor(Age group) 46-55 & $1.624( \pm 0.016)$ & $<0.001$ & $1.611( \pm 0.0017)$ & $<0.001$ \\
\hline factor(Age group) 56-65 & $1.575( \pm 0.015)$ & $<0.001$ & $1.521( \pm 0.0017)$ & $<0.001$ \\
\hline factor(Age group) 65+ & $1.483( \pm 0.015)$ & $<0.001$ & $1.480( \pm 0.0017)$ & $<0.001$ \\
\hline \multicolumn{5}{|l|}{ Residence } \\
\hline urban & ref & ref & ref & ref \\
\hline rural & $1.645( \pm 0.018)$ & $<0.001$ & $1.599( \pm 0.023)$ & $<0.001$ \\
\hline
\end{tabular}


had never measured their BP, compared with $48.1 \%$ of urban residents [23].

Overall, these findings call for the urgent launch of a national BP control programme to formulate and implement multisectoral evidence-informed public health interventions geared towards the primary prevention of hypertension. Such interventions that are centred on lifestyle modifications would include physical activity, healthy diets rich in fruits and vegetables, low fat dairy products, reduced saturated fats and reduced dietary salt intake [24]. Currently, there is no evidence for pharmacological therapy for prehypertension except in very high risk patients.

The main strength of this study is the regional distribution of study participants, with representation from more than a third of all the counties in Kenya. This allows for in-country generalisability of findings and provides a strong evidence base to inform discussions on policies and guidelines for preventing cardiovascular disease risks.

Our study had a number of limitations, mostly inherent to the study design. First, due to the retrospective nature of the study, data on crucial known risk factors for prehypertension, including smoking, alcohol intake, body mass index, physical activity and dietary factors, were not collected. These were therefore not included in the regression model, hence affecting control for confounding. Second, the HHA data collection was crosssectional. This implies that BP classification was based on readings that were recorded during a single sitting per participant. This could have resulted in an overestimate of prehypertension, as some of the elevated BP recordings documented within facility settings could have been the result of transient elevations [25]. Finally, although we report on about 6 million participants, the programme participants were drawn from a convenient sample in the context of a population BP screening programme. However, the distribution of BP was similar to previous national representative survey [23].

\section{Conclusions}

Approximately one in two Kenyan adults has prehypertension, and it starts at a very young age. This calls for urgent public health mitigation strategies in order to avert prehypertension-associated morbidity and mortality. Further studies are needed to better define the role of traditional and novel anthropometric, biochemical and environmental risk factors in the causation of prehypertension and to identify the determinants and rate of regression of prehypertension to normal BP or regression to overt hypertension.

\section{Abbreviations}

aOR: Adjusted odds ratio; BP: Blood pressure; HCW: Healthcare worker; HHA: Healthy Heart Africa; SD: Standard deviation

\section{Acknowledgements}

The authors wish to thank Dr. Nelson Otieno (Healthy Heart Africa, AstraZeneca) for critically reviewing the manuscript; the funding agency, AstraZeneca; the Kenya Ministry of Health; participating County Departments of Health and implementing partners: AMPATH (Moi University), JHPIEGO, Christian Health Association of Kenya (CHAK), AMREF, PSI Kenya; the Mission for Essential Drugs and Supplies (MEDS); Abt Associates and Savanna Informatics Limited.

\section{Authors' contributions}

GY and ENO conceptualized the study; JOM, ENK and COO analysed the data; JOM, ENK and FGK interpreted the data and wrote the first draft of the manuscript; JOM, KN, GY and ENO reviewed and substantively revised the manuscript. All authors read and approved the final manuscript.

\section{Funding}

This study was funded by AstraZeneca PLC. The funding agency did not play any role in data collection, analysis and interpretation.

\section{Availability of data and materials}

All data generated or analysed during the current study are available from the sponsoring agencies on request though the corresponding author.

\section{Ethics approval and consent to participate}

Approval for the study was granted by the Kenyatta National Hospital/ University of Nairobi Ethics and Research Committee. Waiver of written informed consent was granted because the research involved no more than minimal risk; the waiver would not adversely affect the rights and welfare of the subjects; and it would be impracticable to conduct the research without the waiver.

\section{Consent for publication}

Not applicable.

\section{Competing interests}

Kennedy Njau is an employee of AstraZeneca. The other authors have no competing interests.

\section{Author details}

'Department of Clinical Medicine and Therapeutics, University of Nairobi, Nairobi, Kenya. ${ }^{2}$ Healthy Heart Africa, Nairobi, Kenya.

Received: 28 October 2019 Accepted: 17 February 2020

Published online: 03 March 2020

\section{References}

1. Zhou M, Wang $H$, Zeng $X$, Yin P, Zhu J, Chen W, et al. Mortality, morbidity, and risk factors in China and its provinces, 1990-2017: a systematic analysis for the global burden of disease study 2017. Lancet. 2019:394(10204):1145-58.

2. World Health Organization. A global brief on hypertension: silent killer, global public health crisis. Geneva: WHO; 2013. Available at: http://apps. who.int/iris/bitstream/10665/79059/1/WHO_DCO_WHD_2013.2_eng. pdf?ua=1. [cited January 30 2020].

3. Ataklte F, Erqou S, Kaptoge S, Taye B, Echouffo-Tcheugui JB, Kengne AP. Burden of undiagnosed hypertension in sub-Saharan Africa: a systematic review and meta-analysis. Hypertension. 2015;65:291-8.

4. Wamai RG, Kengne AP, Levitt N. Non-communicable diseases surveillance: overview of magnitude and determinants in Kenya from STEPwise approach survey of 2015. BMC Public Health. 2018;18(3):1224.

5. Ogola EN, Barasa F, Barasa AL, Gitura BM, Njuguna B, Beaney T, et al. May Measurement Month 2017: the results of blood pressure screening of 14 845 individuals in Kenya-Sub-Saharan Africa. Eur Heart J Suppl. 2019; 21(Suppl D):D71-3.

6. Chobanian AV, Bakris GL, Black HR, Cushman WC, Green LA, Izzo JL Jr, et al. The seventh report of the joint National Committee on prevention, detection, evaluation, and treatment of high blood pressure: the JNC 7 report. JAMA. 2003;289(19):2560-72.

7. Svetkey LP. Management of prehypertension. Hypertension. 2005;45:1056-61.

8. Financing Global Health Data Visualization. 2018. Available from: https:// vizhub.healthdata.org/fgh/. [cited January 30 2020]. 
9. Onyango MJ, Kombe I, Nyamongo DS, Mwangi M. A study to determine the prevalence and factors associated with hypertension among employees working at a call Centre Nairobi Kenya. Pan Afr Med J. 2017;27:178.

10. Joshi MD, Ayah R, Njau EK, Wanjiru R, Kayima JK, Njeru EK, et al. Prevalence of hypertension and associated cardiovascular risk factors in an urban slum in Nairobi, Kenya: a population-based survey. BMC Public Health. 2014;14:1177.

11. Ogola EN, Okello FO, Herr JL, Macgregor-Skinner E, Mulvaney A, Yonga G. Healthy heart Africa-Kenya: a 12-month prospective evaluation of program impact on health care providers' knowledge and treatment of hypertension. Glob Heart. 2019;14(1):61-70.

12. Smith L. New AHA recommendations for blood pressure measurement. Am Fam Physician. 2005;72(7):1391-8.

13. Mainous AG III, Everett CJ, Liszka H, King DE, Egan BM. Prehypertension and mortality in a nationally representative cohort. Am J of Cardiol. 2004;94(12): 1496-500.

14. Wang Y, Wang QJ. The prevalence of prehypertension and hypertension among US adults according to the new joint national committee guidelines: new challenges of the old problem. Arch Intern Med. 2004 164(19):2126-34.

15. Choi KM, Park HS, Han JH, Lee JS, Lee J, Ryu OH, et al. Prevalence of prehypertension and hypertension in a Korean population: Korean National Health and nutrition survey 2001. J Hypertens. 2006;24(8):1515-21.

16. Nuwaha F, Musinguzi G. Pre-hypertension in Uganda: a cross-sectional study. BMC Cardiovasc Disord. 2013;13:101

17. Tsai PS, Ke TL, Huang CJ, Tsai JC, Chen PL, Wang SY, et al. Prevalence and determinants of prehypertension status in the Taiwanese general population. J Hypertens. 2005;23(7):1355-60.

18. Ferguson TS, Tulloch-Reid MK, Younger NO, McFarlane SR, Francis DK, Wilks RJ. Prehypertension in Jamaica: a review of data from recent studies. West Indian Med J. 2011;60(4):429-33.

19. Grotto I, Grossman E, Huerta M, Sharabi Y. Prevalence of prehypertension and associated cardiovascular risk profiles among young Israeli adults. Hypertension. 2006;48(2):254-9.

20. Sun Z, Zheng L, Wei Y, Li J, Zhang $X$, Zhang $X$, et al. Prevalence and risk factors of the rural adult people prehypertension status in Liaoning Province of China. Circ J. 2007;71(4):550-3.

21. Agyemang C, Owusu-Dabo E. Prehypertension in the Ashanti region of Ghana, West Africa: an opportunity for early prevention of clinical hypertension. Public Health. 2008;122(1):19-24

22. Lam CS, Cheng S, Choong K, Larson MG, Murabito JM, Newton-Cheh C, et al. Influence of sex and hormone status on circulating natriuretic peptides. J Am Coll of Cardiol. 2011;58(6):618-26.

23. Kenya Ministry of Health, Kenya National Bureau of Statistics, World Health Organization. Kenya STEPwise survey for non-communicable diseases risk factors 2015 report 2015. Available at: http:/www.health.go.ke/wp-content/ uploads/2016/04/Steps-Report-NCD-2015.pdf. [cited January 30 2019].

24. Appel LJ, Moore TJ, Obarzanek E, Vollmer WM, Svetkey LP, Sacks FM, et al. A clinical trial of the effects of dietary patterns on blood pressure. DASH collaborative research group. N Engl J Med. 1997;336(16):1117-24.

25. O'Brien E, Parati G, Stergiou G, Asmar R, Beilin L, Bilo G, et al. European Society of Hypertension position paper on ambulatory blood pressure monitoring. J Hypertens. 2013;31(9):1731-68.

\section{Publisher's Note}

Springer Nature remains neutral with regard to jurisdictional claims in published maps and institutional affiliations.

Ready to submit your research? Choose BMC and benefit from:
- fast, convenient online submission
- thorough peer review by experienced researchers in your field
- rapid publication on acceptance
- support for research data, including large and complex data types
- gold Open Access which fosters wider collaboration and increased citations
- maximum visibility for your research: over 100M website views per year
At BMC, research is always in progress.
Learn more biomedcentral.com/submissions

